\title{
Aborto em vacas na intoxicação experimental pelas favas de Stryphnodendron obovatum (Leg. Mimosoideae) ${ }^{1}$
}

\author{
Carlos H. Tokarnia ${ }^{2}$, Marilene F. Brito ${ }^{3}$, David Driemeier ${ }^{4}$, Jaime B.D. Costa ${ }^{5}$ \\ e Agostinho J.R. Camargo ${ }^{6}$
}

\begin{abstract}
Tokarnia C.H., Brito M.F., Driemeier D., Costa J.B.D. \& Camargo A.J.R. 1998. [Abortion in cows during experimental poisoning by the pods of Stryphnodendron obovatum (Leg. Mimosoideae).] Aborto em vacas na intoxicação experimental pelas favas de Stryphnodendron obovatum (Leg. Mimosoideae). Pesquisa Veterinária Brasileira 18(1):35-38. Projeto Sanidade Animal Embrapa/UFRRJ, Km 47, Seropédica, RJ 23851-970, Brazil.

The ripe pods of Stryphnodendron obovatum Benth. collected in Mato Grosso, were given to seven cows 3 to 7 months in calf, at the dose of $5 \mathrm{~g} / \mathrm{kg} /$ day, during 9 to 26 days. They caused a disease characterized by decrease in ruminal activity and appetite, salivation, difficulty in getting up, unstable gait, muscular tremors, loss of weight and in 3 of the 7 cows abortion between 20 and 30 days after the beginning of the administration of the pods; a fourth cow expelled a mumified fetus 7 months after the start of the experiment. In the aborted fetuses and in the placentas no significant macroscopic and microscopic lesions were detected. These experiments confirm the informations obtained on farms in the cerrado regions of the States of São Paulo and Mato Grosso, which say that abortion occurs in cows which consume the pods of S. obovatum.
\end{abstract}

INDEX TERMS: Abortion, Stryphnodendron obovatum, plant poisoning, cattle.

RESUMO.- As favas maduras de Stryphnodendron obovatum Benth. procedentes de Mato Grosso, administradas a sete vacas com 3 a 7 meses de gestação, na dose de $5 \mathrm{~g} / \mathrm{kg} / \mathrm{dia}$, durante 9 a 26 dias, causaram doença caractrizada por diminuição do apetite, diminuição da atividade ruminal, sialorréia, dificuldade em se levantar, andar desequilibrado, tremores musculares, acentuado emagrecimento e finalmente em 3 das 7 vacas, aborto entre 20 e 30 dias após o início da administração das favas; uma quarta vaca eliminou um feto mumificado 7 meses após o início do experimento. Três vacas deram nascimento a bezerros normais. Nos fetos abortados e nas placentas não foram verificadas lesões macroscópicas ou

\footnotetext{
${ }^{1}$ Aceito para publicação em 28 de novembro de 1997.

2 Depto Nutrição Animal e Pastagem, Universidade Federal Rural do Rio de Janeiro (UFRRJ), Km 47, Seropédica, RJ 23851-970; bolsista do CNPq (305010/ 76-VT).

${ }^{3}$ Depto Epidemiologia e Saúde Pública, Setor de Anatomia Patológica, UFRRJ.

${ }^{4}$ Depto Clínica e Patologia, Univ. Fed. Rio Grande do Sul, Cx. Postal 15094, Porto Alegre, RS 91540-000.

${ }^{5}$ EMPAER, Cuiabá, MT 78060-000.

6 PESAGRO, Km 47, Seropédica, RJ 23851-970.
}

microscópicas dignas de nota. Os presentes experimentos confirmam as informações obtidas em fazendas do cerrado nos Estados de São Paulo e Mato Grosso sobre a ocorrência de aborto em vacas que ingerem as favas de $S$. obovatum.

TERMOS DE INDEXAÇÃO: Aborto, Stryphnodendron obovatum, plantas tóxicas, bovino.

\section{INTRODUÇÃO}

As favas de diversas leguminosas arbóreas, especialmente de Dimorphandra mollis, Enterolobium contortisiliquum e Stryphnodendron obovatum com frequencia são acusadas de causarem aborto em vacas. Os experimentos realizados em vacas com as favas de $D$. mollis e E. contortisiliquum para comprovar este efeito, até agora resultaram negativos.

As favas de $D$. mollis foram administradas por via oral a nove vacas prenhes (três estavam ao redor do $90^{\circ}$, três do $150^{\circ}$ e três do $210^{\circ}$ dia de gestação) em doses únicas de 10 e $12 \mathrm{~g} / \mathrm{kg}$; nenhuma delas abortou, porém algumas adoeceram e duas morreram (Santos et al. 1978).

As favas de E. contortisiliquum foram administradas a três vacas gestantes - os autores não indicam em que fase de gestação se encontravam - na dosagem de $10 \mathrm{~g} / \mathrm{kg}$ por dia, durante um período de 30 dias. 0 único sintoma observado foi 
diarréia em duas das três vacas, sem, no entanto, ocorrer mortes ou abortos. (Marques et al. 1974)

Não havia estudo experimental sobre a ação abortiva das favas de $S$. obovatum em bovinos.

Uma grande dificuldade no planejamento de experimentos em que se procura reproduzir o aborto com as favas das leguminosas arbóreas acima mencionadas, é a escassez de históricos com dados mais precisos.

Em visitas às regiões de ocorrência de S. obovatum (São Paulo e Mato Grosso), constatamos que os bovinos comem avidamente as favas desta árvore caídas no chão, na época de seca. Observamos, que nessas regiões nesta época há muitos bovinos com emagrecimento exagerado. Verificamos que as favas de $S$. obovatum com frequência são acusadas de causar aborto em vacas. (M.F. Brito)

De acordo com informações obtidas na região de Cuiabá, Mato Grosso, em fazendas do cerrado com pastagens nativas em que vacas ingerem as favas de $S$. obovatum, o índice de aborto é alto. Os abortos são verificados em todas as fases de gestação, porém são melhor observados no final da gestação. (M.F. Brito)

Um histórico de Rondonópolis, Mato Grosso, em relação Stryphnodendron obovatum, informa que algumas vacas se viciam em comer as favas desta árvore, não saem embaixo das árvores de $S$. obovatum, emagrecem muito e acabam abortando. Diz que as vacas não morrem, que só ficam com estado geral muito debilitado. (I.S. Brito 1996)

No presente estudo as favas de Stryphnodendron obovatum foram administradas por via oral a vacas gestantes para verificar se a sua ingestão tem como consequência o aborto.

\section{MATERIAL E MÉTODOS}

Sete vacas mestiças holandesas preto e branco, em diversas fases de gestação, receberam as favas maduras de Stryphnodendron obovatum Benth. (Leg. Mimosoideae) durante períodos variáveis na dosagem de $5 \mathrm{~g} / \mathrm{kg} / \mathrm{dia}$. Pouco antes de sua administração as favas eram moídas e umedecidas; eram colocadas na boca dos animais, que então as deglutiam. Optou-se pela dosagem de $5 \mathrm{~g} / \mathrm{kg} / \mathrm{dia}$, pois em experimentos realizados anteriormente em bezerros, verificou-se que a dose de $10 \mathrm{~g} / \mathrm{kg} / \mathrm{dia}$ causou a morte quando administrada durante 8 dias seguidos; a dose de $5 \mathrm{~g} / \mathrm{kg} /$ dia durante 14 dias causou doença, porém o animal se recuperou (M.F. Brito 1997). As favas procediam da região de Nossa Senhora do Livramento, Mato Grosso, e foram sempre da última safra que precedia a realização dos experimentos.

Antes do começo do experimento as vacas e o touro foram submetidos a exames de brucelose, tricomoníase, campilobacteriose, todos com resultados negativos. Foram realizados ainda exames sorológicos para IBR, BVD e leptospirose. Para IBR e BVD todos deram resultados negativos. A vaca 5212 reagiu para Leptospira bratislava, $L$. hardjo e $L$. Wolffi (reagentes na diluição de 1:100). As amostras do touro e das vacas $5224,5276,5277,5278,5285$ e 5286 não reagiram a $L$. bratislava, $L$. hardjo e $L$. Wolffi e, como a vaca 5212 , também não a $L$. australis, $L$. autummalis, $L$. canicola, $L$. Grippotyphosa, $L$. pomona, $L$. icterohaemorrhagiae e L. tarassovi.

Através da palpação retal era determinada a fase de gestação.

Durante o período experimental as vacas eram examinadas diariamente relativo a temperatura, frequência dos batimentos cardíacos, frequência respiratória e atividade do rúmen. Eram observadas as fezes e avaliado o consumo do capim picado oferecido no cocho, bem como o comportamento dos animais de uma maneira geral. Quando os animais apresentavam diminuição acentuada do apetite, a administração das favas era interrompida e se oferecia capim-angola (Brachiaria mutica) não picado e se colocava as vacas

Quadro 1. Experimentos em vacas gestantes com as favas de Stryphnodendron obovatum

\begin{tabular}{|c|c|c|c|c|c|c|c|c|}
\hline $\begin{array}{c}\text { Bovino } \\
\text { no. } \\
\text { (reg. SAP) }^{\mathrm{a}}\end{array}$ & $\begin{array}{c}\text { Peso } \\
\text { kg }\end{array}$ & $\begin{array}{l}\text { Idade } \\
\text { em } \\
\text { anos }\end{array}$ & $\begin{array}{l}\text { Fase de gestação } \\
\text { no começo do } \\
\text { experimento }\end{array}$ & $\begin{array}{c}\text { Período das } \\
\text { administrações }\end{array}$ & $\begin{array}{c}\text { Número de } \\
\text { administrações } \\
\text { de } 5 \mathrm{~g} / \mathrm{kg} / \mathrm{dia}\end{array}$ & $\begin{array}{l}\text { Início de sinto- } \\
\text { mas após come- } \\
\text { ço das admi- } \\
\text { nistrações }\end{array}$ & $\begin{array}{l}\text { Desfecho em rela- } \\
\text { ção a gestação }\end{array}$ & $\begin{array}{l}\text { Aborto após } \\
\text { início das } \\
\text { administra- } \\
\text { ções (dias) }\end{array}$ \\
\hline $\begin{array}{c}5276 \\
(27689)\end{array}$ & 361 & $8-9$ & 3 meses & 22.3-9.4.95 & 18 & 7 & $\begin{array}{l}\text { Aborto em } \\
\text { 21.4.95 }\end{array}$ & 30 \\
\hline $\begin{array}{c}5278 \\
(28092)\end{array}$ & 385 & $5-6$ & 5 meses & $16.10-24.10 .95$ & 9 & 4 & $\begin{array}{l}\text { Expelido feto } \\
\text { mumificado em } \\
10.5 .96\end{array}$ & \\
\hline 5277 & 418 & 16 & 4 meses & 16.10-2.11.95 & 18 & 11 & $\begin{array}{l}\text { Deu cria a uma } \\
\text { fêmea normal } \\
\text { em } 14.4 .96\end{array}$ & \\
\hline $\begin{array}{c}5212 \\
(28251-52)\end{array}$ & 325 & $3-4$ & 3 meses & 11.9-6.10.96 & 26 & 18 & $\begin{array}{l}\text { Aborto em } \\
21.10 .96\end{array}$ & 20 \\
\hline $\begin{array}{c}5224 \\
(28254-56)\end{array}$ & 323 & 3 & 7 meses & 27.9-11.10.96 & 15 & 12 & $\begin{array}{l}\text { Aborto em } \\
23.10 .96\end{array}$ & 26 \\
\hline 5285 & 403 & 3 & 5 meses & 26.5-18.6.97 & 24 & 12 & $\begin{array}{l}\text { Deu cria a um } \\
\text { macho normal } \\
\text { em 26.9.97 }\end{array}$ & \\
\hline 5286 & 542 & 6 & 4 meses & $26.5-6.6 .97$ & 12 & 9 & $\begin{array}{l}\text { Deu cria a um } \\
\text { macho normal } \\
\text { em } 1.11 .97\end{array}$ & \\
\hline
\end{tabular}

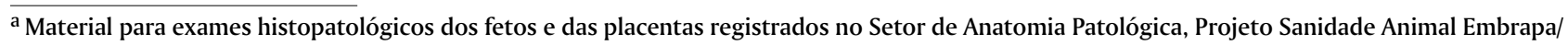
UFRRJ. 
durante parte do dia em piquete para pastar. A três vacas (Bov. 5278, $5212,5224)$ foi administrada por via oral durante alguns dias, na fase de maior diminuição de apetite, capim-angola e conteúdo ruminal de bovinos sadios. Especial atenção era dada à ocorrência de aborto.

\section{RESULTADOS}

Os dados mais importantes sobre os experimentos em que as favas de Stryphnodendron obovatum foram administradas a sete vacas em diversas fases de gestação, constam do Quadro 1 .

Um resumo dos dados experimentais das sete vacas consta a seguir.

Bovino 5276, com 8 a 9 anos de idade, peso de $361 \mathrm{~kg}$, e com 3 meses de gestação, recebeu de 22.3 a 9.4 .95 , isto é, durante 18 dias seguidos, $5 \mathrm{~g} / \mathrm{kg} /$ dia (1850 g) das favas moídas de Stryphnodendron obovatum. A partir de 29.3.95 começou a apresentar diminuição do apetite. A partir de 1.4 .95 mostrou sialorréia, que se foi acentuando a cada dia. A partir de 4.4 .95 se observou ocasionalmente mastigação vazia. Em 9.4.95 o animal apresentou falta de apetite acentuada, sialorréia e mastigação vazia. Nesse dia foi administrada a fava pela última vez. Nos dias seguintes o animal foi recuperando o apetite. Em 21.4.95 de manhã foi encontrado um feto abortado, bastante autolizado. A vaca continuou a se alimentar bem e a recuperar o seu peso.

Bovino 5278 , com 5 a 6 anos de idade, peso de $385 \mathrm{~kg}$, e com 5 meses de gestação, recebeu de 16.10 a 24.10.95, isto é, durante 9 dias seguidos, $5 \mathrm{~g} /$ $\mathrm{kg} / \mathrm{dia}$ (1925 g) das favas moídas de S. obovatum. A partir de 20.10 .95 observou-se diminuição de apetite, que progressivamente foi se acentuando. No dia 24.10.95 a diminuição de apetite era muito acentuada e a ativiade ruminal diminuída em relação a frequência e intensidade dos movimentos; neste dia a fava foi administrada pela última vez. Solto no piquete, o animal continuou com acentuada falta de apetite. A partir de 27.10.95 notou-se andar desequilibrado; além disto o animal estava irrequieto. Em 30.10.95 continuou mostrando grande falta de apetite, tinha andar cambaleante, filete de saliva escorria pela boca, havia tremores musculares nos membros. A partir de 4.11.95, isto é, após a administração por via oral de capim-angola e conteúdo ruminal, o animal começou a recuparar o apetite. Ainda mostrou tremores musculares e sialorréia. Em 9.11.95 foi considerado recuperado. Em 25.4.96, feita palpação, foi levantada a suspeita de presença de feto mumificado. Em 10.5.96 às 10:00 h foi encontrado feto mumificado no piquete. A vaca sempre continuou a pastar bem.

Bovino 5277, com 16 anos de idade, peso de $418 \mathrm{~kg}$, e com 4 meses de gestação, recebeu de 16.10 a 2.11 .95 , isto é, durante 18 dias seguidos, $5 \mathrm{~g} /$ $\mathrm{kg} / \mathrm{dia}(2090 \mathrm{~g})$ das favas moídas de $S$. obovatum. A partir de 27.10.95 observou-se leve diminuição de apetite. A partir de 29.10 .95 verificou-se que as fezes estavam semi-líquidas. A última administração da fava foi feita em 2.11.95. Neste dia notou-se sialorréia. As fezes aumentaram um pouco de consistência, mas continuavam muito moles. A partir de 9.11 .95 comia bem, as fezes assumiram consistência normal. Em 14.4.96 deu cria a uma fêmea normal.

Bovino 5212, com 3 a 4 anos de idade, peso de $325 \mathrm{~kg}$, e com 3 meses de gestação, recebeu de 11.9 a 6.10 .96 , isto é, durante 26 dias seguidos, $5 \mathrm{~g} / \mathrm{kg} /$ dia (1625 g) das favas moídas de $S$. obovatum. A partir de 29.9 .96 observou-se leve diminuição de apetite que se foi acentuando com o passar dos dias; em 6.10.96 comia muito pouco do capim picado, porém comia bem o capimangola inteiro. Áreas despigmentadas do focinho, bem como da mucosa bucal, moderadamente avermelhadas. Em 6.10.96 foi interrompida a administração da fava. A falta de apetite continuou nos próximos dias; a atividade ruminal era diminuída, em relação à frequência e intensidade dos bracejos. A partir de 8.10 .96 o animal se levantava com dificuldade e caminhava com dificuldade com os membros posteriores, manifestando certo desequilíbrio. Em 9.10.96 notou-se vermelhidão e leve edema na parte superior aos cascos. Nos próximos dias a diminuição do apetite foi se acentuando, o animal comendo muito pouco. A partir de $\mathbf{1 0 . 1 0 . 9 6}$ verificou-se sialorréia. $O$ animal demonstrou leve agressividade, estava irrequieto, e custava a levantar-se quan- do tocado. De 12.10 a 16.10 .96 foi dado ao animal, na boca, capim-angola, e em 16 e 17.10 .96 conteúdo ruminal. Em 14.10 .96 foi observado corrimento gelatinoso e transparente pela vagina. $\mathrm{O}$ animal estava muito magro. Em 18.10.96 foi observado abundante cordão de muco turvo grosso penderado pela vulva. Em 21.10.96 de manhã foi encontrado um feto com placenta abortado. A partir desta data o animal foi recuperando o apetite, pastando bem e recuperando o peso.

Bovino 5224, com 3 anos de idade, peso de $323 \mathrm{~kg}$, e com gestação de 7 meses, recebeu de 27.9 a 11.10 .96 , isto é, durante 15 dias seguidos, $5 \mathrm{~g} / \mathrm{kg}$ / dia (1660 g) das favas moídas de $S$. obovatum. A partir de 9.10 .96 o animal mostrou leve diminuição de apetite, não comendo todo o capim picado, mas comendo capim-angola inteiro oferecido e pastava. A partir de 11.10.96 notou-se certa dificuldade para se levantar. Neste dia foi interrompida a administração da fava. A partir de 14.10 .96 notou-se sialorréia intensa ao ponto de a saliva formar poças no chão. A atividade ruminal, a frequência dos batimentos cardíacos, a frequência respiratória, bem como a temperatura estavam normais. De 14.10 a 16.10 .96 foi dado ao animal, na boca, capimangola e em 16.10 e 17.10 .96 conteúdo ruminal. A partir de 20.10.96 a vaca demonstrou maiores dificuldades de se levantar, ficava durante muito tempo em decúbito esternal. Apresentava tremores da mandíbula. Mas ocasionalmente se levantava e pastava. Em 23.10.96 foi encontrada em decúbito lateral em trabalho de parto, verificando-se um bezerro com somente os membros anteriores e a cabeça expostos. Tracionado o bezerro, este saiu com facilidade, mas só com pequena parte da placenta. Bezerro quase a termo, morto. Foi aplicado antibiótico por via parenteral. Logo em seguida a vaca se levantou e começou a pastar. Em 24.10.96 a vaca amanheceu em decúbito lateral; foi colocada em decúbito esternal. Mais tarde se levantou e foi pastar. À tardinha foi encontrada novamente em decúbito lateral com tremores na mandíbula. A partir de 25.10 .96 o animal começou a ficar mais esperto, pastando bem, porém muito magro. Em 28.10.96 de manhã foi encontrada no chão a placenta. Animal sempre pastando bem, recuperando peso.

Bovino 5285, com 3 anos de idade, peso de $403 \mathrm{~kg}$, e com 5 meses de gestação, recebeu de 26.5 a 18.6 .97 , isto é, durante 24 dias seguidos, $5 \mathrm{~g} / \mathrm{kg}$ / dia (2015 g) das favas moídas de $S$. obovatum. A partir de 7.6 .97 mostrou diminuição de apetite (só comia capim Guatemala inteiro oferecido, e não mais o costumeiro capim Guatemala picado colocado no cocho), ranger de dentes, tremores musculares nas regiões da omoplata e glútea, diminuição da atividade ruminal, fezes menos consistentes que o normal, sialorréia. Estes sintomas com o passar dos dias foram se acentuando, especialmente a sialorréia e o ranger de dentes. Às vezes o animal fazia movimentos vazios de mastigação salivando muito. A partir de 13.6.97 o animal não comia mais capim Guatemala inteiro, só capim-angola inteiro, e a partir de 16.6 .97 mesmo este só em parte. Quando ruminava, espumava muito. A partir de 17.6.97 melhorou o apetite; o animal começou a comer capim Guatemala inteiro e picado, além de todo capim-angola, mas continuou com sialorréia e ranger de dentes. Em 18.6.97 foi administrada a fava pela última vez. Em 19.6.97 o animal comeu quase todo o capim picado; continuou com bom apetite nos dias seguintes; ainda apresentava sialorréia e ocasional ranger de dentes até o dia 23.6.97, quando foi considerado recuperado. Em 3.7 .97 pesou $394 \mathrm{~kg}$. Em 26.9.97 deu cria a um macho normal.

Bovino 5286, com 6 anos de idade, peso de $542 \mathrm{~kg}$, e com 5 meses de gestação, recebeu de 26.5 a 6.6 .97 , isto é, durante 12 dias seguidos, $5 \mathrm{~g} / \mathrm{kg} /$ dia (2710 g) das favas moídas de $S$. obovatum. A partir de 4.6 .97 começou a mostrar diminuição de apetite (não comia mais o costumeiro capim Guatemala picado colocado no cocho, só capim Guatemala inteiro) e ranger de dentes. Continuou com estes sintomas em 5 e 6.6.97. Em 7.6.97 o animal mostrou fases de acentuada apatia, ficava parado, às vezes com a cabeça apoiada na parede, tinha andar desequilibrado quando tocado, caía com facilidade, especialmente quando a cabeça era levantada para o exame das mucosas, tinha dificuldade em se levantar. Por outro lado, tinha fases de agitação, andando muito. Tinha acentuado ranger de dentes. Mostrou acentuada diminuição de apetite (só comeu parte do capim-angola inteiro); foi constatada diminuição da atividade ruminal. A partir deste dia não mais foi administrada a fava. Os sintomas observados em 7.6.97 continuavam mais ou menos com a mesma intensidade até o dia 12.6.97. A partir de 9.6.97 o animal ocasionalmente apresentava ainda tremores musculares, e começou a ter 
sialorréia, que em 12.6.97 era forte. A partir de 13.6.97 os sintomas diminuíram rapidamente a cada dia. Já em 13.6.97 o animal era ativo, não mostrou mais desequilíbrio, comia bem capim, mas ainda tinha forte sialorréia e ranger de dentes. No fim do dia 17.6.97 foi considerado recuperado. Em 3.7.97 pesava $517 \mathrm{~kg}$. Em 1.11.97 deu cria a um macho normal.

Verifica-se, que das sete vacas que receberam as favas de S. obovatum, três abortaram e uma eliminou um feto mumificado.

A administração das favas de $S$. obovatum causou intoxicação nas vacas, com sintomatologia bastante uniforme para todas elas, com início 4 a 8 dias após o começo das administrações e consistindo em diminuição do apetite, diminuição da atividade ruminal, sialorréia, dificuldade em se levantar e andar desequilibrado, tremores musculares e acentuado emagrecimento.

O aborto ocorreu nas três vacas entre 20 e 30 dias após o início da administração das favas. $\mathrm{O}$ aborto ocorreu tanto com fetos de 3 como de 7 meses de idade no início do experimento. As placentas foram eliminadas junto com os fetos, com uma exceção (Bov. 5224), expulsa poucos dias após o aborto.

Os fetos não apresentaram lesões, a não ser edema subcutâneo sobretudo da cabeça (fetos dos Bov. 5276 e 5212) e edema da parede da vesícula biliar (feto do Bov. 5224).

Os exames histopatológicos de órgãos dos fetos e das placentas revelaram ausência de lesões.

\section{DISCUSSÃO}

Os nossos experimentos permitem concluir que a ingestão das favas de Stryphnodendron obovatum em doses de $5 \mathrm{~g} / \mathrm{kg} /$ dia durante períodos de 9 a 26 dias causa intoxicação nos animais capaz de provocar aborto.

Os nossos experimentos confirmam desta maneira a informação do homem do campo que é observado aborto em vacas que ingerem as favas de $S$. obovatum.
Os dados obtidos durante os experimentos permitem suspeitar que as favas de $S$. obovatum não têm ação direta sobre a musculatura uterina ou sobre o feto, mas que o aborto seria uma consequência da grave intoxicação que causa grande debilidade orgânica.

Apesar da ingestão de consideráveis quantidades de $S$. obovatum, nenhuma vaca mostrou sintomas de fotossensibilização, manifestação que também não foi verificada pelas observações de campo de M.F. Brito e I.S. Brito (1996), nem nos experimentos em bezerros de M.F. Brito (1997), desta maneira não confirmando-se observações feitas por Camargo (1965).

Agradecimentos.- Aos Prof. Leonildo Bento Galiza da Silva, Maria Cristina da Silva, da Universidade Federal de Cuiabá, à Prof. Imke Pfeifer Barbosa, da Universidade Federal do Pará em Belém, e à Prof. Vera Teixeira, da Universidade Federal Rural do Rio de Janeiro, pela valiosa colaboração em diversas fases do desenvolvimento do trabalho. Ao Assistente de Pesquisa João Luiz Bastos pela valiosa colaboração nos trabalhos de experimentação. Queremos deixar aqui registrada a participação na parte experimental do trabalho dos alunos bolsistas e estagiários Luis Armando Galvão Brust, Marcos Dutra Duarte, Ticiana Nascimento França, Valíria Duarte Cerqueira, Alexander Pérez González e Bernardo Rosa Melo da Cunha.

\section{REFERÊNCIAS}

Brito I.S. 1996. Comunicação pessoal (Médico-veterinário, Rondonópolis, MT). Brito M.F. 1997. Tese em elaboração (Univ. Fed. Rural do Rio de Janeiro).

Camargo W. 1965. Fotossensibilização em bovinos por "barbatimão" (Stryphnodendron obovatum Benth.); fam. Leguminosae. Biológico, S. Paulo, 31(1):7-11.

Marques D.C., Santos H.L., Couto E.S., Mello M.A., Ribeiro R.M.P. \& Ferreira P.M. 1974. Intoxicação experimental pelo tamboril Enterolobium contortisiliquum Vell. Morong. em bovinos. Arqs Esc. Vet., UFMG, Belo Horizonte, 26(3):283-286.

Santos F.C.C., Fischer P., Fichtner S.S., Santos E.E. \& Veiga L.S. 1978. Efeitos negativos da fava da faveira (Dimorphandra mollis) em condições experimentais, como causa de aborto em vacas. Anais XV Congr. Bras. Med. Vet., Rio de Janeiro, out. 1976, p. 31. (Resumo) 